\title{
Longitudinal relationships between self-concept for physical activity and neighborhood social life as predictors of physical activity among older African American adults
}

\author{
Allison M. Sweeney ${ }^{1 *}$, Dawn K. Wilson ${ }^{1}$ and M. Lee Van Horn²
}

\begin{abstract}
Background: Engaging in regular physical activity (PA) as an older adult has been associated with numerous physical and mental health benefits. The aim of this study is to directly compare how individual-level cognitive factors (self-efficacy for PA, self-determined motivation for PA, self-concept for PA) and neighborhood perceptions of the social factors (neighborhood satisfaction, neighborhood social life) impact moderate-to-vigorous physical activity (MVPA) longitudinally among older African American adults.
\end{abstract}

Methods: Data were analyzed from a sub-set of older African American adults ( $N=224, M_{\text {age }}=63.23$ years, $S D=8$. $74,63.23 \%$ female, $M_{\text {Body }}$ Mass Index $=32.01$, SD $=7.52$ ) enrolled in the Positive Action for Today's Health trial. MVPA was assessed using 7-day accelerometry-estimates and psychosocial data (self-efficacy for PA, self-determined motivation for PA, self-concept for PA, neighborhood satisfaction, neighborhood social life) were collected at baseline, 12-, 18-, and 24-months.

Results: Multilevel growth modeling was used to examine within- and between-person effects of individual-level cognitive and social environmental factors on MVPA. At the between-person level, self-concept $(b=0.872, S E=0$. $239, p<0.001)$, and neighborhood social life $(b=0.826, S E=0.176, p<0.001)$ predicted greater MVPA, whereas neighborhood satisfaction predicted lower MVPA $(b=-0.422$, SE $=0.172, p=0.015)$. Among the between-person effects, only average social life was moderated by time $(b=0.361, S E=0.147, p=0.014)$, indicating that the impact of a relatively positive social life on MVPA increased across time. At the within-person level, positive increases in self-concept $(b=0.294, S E=0.145, p=0.043)$ and neighborhood social life $(b=0.270, S E=0.113, p=0.017)$ were associated with increased MVPA.

Conclusions: These results suggest that people with a higher average self-concept for PA and a more positive social life engaged in greater average MVPA. Additionally, changes in perceptions of one's neighborhood social life and one's self-concept for PA were associated with greater MVPA over 2 years. These factors may be particularly relevant for future interventions targeting long-term change and maintenance of MVPA in older African Americans.

Trial registration: ClinicalTrials.Gov \#NCT01025726 registered 1 December 2009.

Keywords: Physical activity, Neighborhood Social Environment, Self-concept, Older adults

\footnotetext{
* Correspondence: sweeneam@mailbox.sc.edu

'Department of Psychology, University of South Carolina, 1233 Washington

Street, 9th Floor, Columbia, SC 29208, USA

Full list of author information is available at the end of the article
} 


\section{Background}

The numerous benefits of engaging in regular physical activity (PA) are apparent across the lifespan. Among older adults, PA is associated with numerous physical health benefits, including a significant reduction in risk for all-cause mortality, cardiovascular disease, stroke, and type two diabetes [1-4]. Large-scale longitudinal studies have demonstrated that the benefits of PA are cumulative, such that for every additional $15 \mathrm{~min}$ of daily PA, the risk of mortality from any cause decreases by $4 \%$ [5]. Furthermore, among older adults PA is associated with a reduced risk of falls and faster recovery from functional limitations, thereby helping older adults to increase the number of years of independent living $[1,6]$. Older adults who engage in regular PA also benefit further from a reduced risk of depression [7], improved cognitive functioning $[8,9]$ including improved memory and hippocampal growth [10], and experience higher levels of well-being [11].

Despite the significant physical and mental health benefits, engagement in regular PA decreases with age $[12,13]$. In the United States, it is estimated that approximately $28 \%$ of adults aged 50 years and older are inactive, with inactivity increasing with age from $25.4 \%$ among adults aged 50-64 years, 26.9\% among those aged $65-74$ years, and $35.3 \%$ among those aged $\geq 75$ years [14]. A systematic review of 53 studies from 15 countries revealed that the percentage of adults aged $\geq 60$ years meeting the guidelines for daily PA ranged from $2.4 \%$ to $83 \%$ with the majority of studies reporting that $40-80 \%$ of the samples were failing to meet PA guidelines [15]. In the United States, physical inactivity and the related health consequences are particularly problematic for African Americans, as African Americans are less likely to meet national PA guidelines [16], and are at a significantly higher risk for morbidity and mortality, including higher rates of obesity, type 2 diabetes, and pre-mature death $[17,18]$. Health disparities remain a major concern across the lifespan, but may have particularly detrimental effects among older adults, given the higher levels of physical, cognitive, and economic vulnerabilities that accompany older adulthood relative to younger adulthood [19].

Interventions for promoting PA among older adults can be organized from individual-level approaches (e.g., attitudinal, psychological and behavioral factors) through environmental approaches (e.g., neighborhood, built, and social environmental factors) [20]. Whereas some factors, such as PA enjoyment and access to facilities, predict both PA initiation and maintenance among older adults, other factors, such as outcome expectations and action-planning, are more strongly associated with PA initiation than maintenance [21]. Such findings suggest that the determinants of PA among older adults may change over time. At the individual-level, numerous studies have found that self-efficacy, or confidence in one's capacity to carry out a behavior [22, 23], plays a critical role in PA initiation and maintenance among older adults [25, 26]. Social Cognitive Theory proposes that when people are high in self-efficacy, they are more likely to believe that they can master challenging problems and recover quickly from setbacks [22, 23]. Consistent with this model, among older White adults, high self-efficacy for PA is associated with exercise adherence even after a formal exercise program has finished [24, 25]. Similarly, other studies have found that active older White adults are more likely to be high in self-efficacy for PA than those who are inactive [26]. Furthermore, self-efficacy for PA among White older adults has been associated with exercise adherence across a three-year period [27].

Examining older adult's motivation for engaging in regular PA has provided additional insight into individual-level factors that promote PA among older adults. SelfDetermination Theory posits that behavior should be more stable when people's motivation is guided by more autonomous (rather than controlled) reasons [28]. That is, people are more likely to engage in PA when they view PA as important, enjoyable, and consistent with their values, rather than an obligation or a means to avoid disapproval from others [29, 30]. Interventions which promote autonomous motivation by allowing participants to have self-directed choice in their PA have proven to be successful for increasing PA across 1 year among older adults [31]. Further underscoring the importance of selfdetermined motivation for PA among older adults, several studies comprised primarily of older White adults have shown that among individuals coping with chronic illness, those who engage in PA for more autonomous reasons tend to be more physically active [33]. For example, among breast cancer survivors, older women meeting daily PA guidelines had significantly greater autonomous motivation for PA than inactive women [32]. Similarly, among rheumatoid arthritis outpatients, autonomous motivation for PA was positively associated with greater engagement in PA [33]. Furthermore, one prospective study of cardiac rehabilitation outpatients found that autonomous motivation for PA at the end of an exercise rehabilitation program was positively associated with higher levels of PA at follow-up after a six-week period [34].

PA may also depend upon the extent to which PA engagement is viewed as critical to one's self-concept. Identity theory [35] proposes that the more important any one self-aspect is to one's overall sense of self, the more likely it is that behaviors associated with that selfaspect will be repeated. Consistent with this model, numerous studies have found that among children and adolescents a positive self-concept for PA predicts future 
exercise behavior [36, 37], with some studies finding longitudinal effects spanning across 13 years [38]. Similarly, among young adults, those with a positive self-concept for a particular activity (e.g., aerobic exercise) are more likely to engage in that specific activity [39]. However, predictors of PA among adolescents and younger adults may differ from those of older adults. As roles change across the lifespan (e.g., as one transitions from being a parent to a grandparent), individuals' self-concepts may continue to evolve [40]. However, other roles or activities are not explicitly age-specific and may continue to be a critical component of the self-concept among older adults. For example, among older adults, leisure activities have been found to be especially important for shaping the self-concept $[41,42]$ and are increasingly mentioned as important descriptors of the self [43]. In light of these findings, a positive self-concept for PA may be especially important in older adulthood; yet, few studies have examined self-concept for PA among older adults.

Social Cognitive Theory proposes that an individual's behavior interacts with both individual-level cognitive factors and influences from the environment [22, 23]. There is increasing cross-sectional evidence that among older adults various aspects of the neighborhood environment, including perceived neighborhood walkability, safety, and access to recreational facilities, impact walking and PA [44-46]. Importantly, aspects of the physical environment interact with individual-level and social environmental factors to influence PA engagement among older adults. A cross-sectional study of predominantly White community-dwelling adults found that among older adults living in supportive built environments (i.e., high walkability, positive neighborhood aesthetics, access to facilities), those with a positive social environment (i.e., high social support) engaged in greater minutes of MVPA per week [47].

Thus, in addition to perceptions of the physical environment, perceptions of the neighborhood social environment may also impact PA among older adults. Neighborhood social cohesion, or mutual trust and solidarity among neighbors and positive supportive social connections and interactions [48], has been associated with greater levels of walking behavior between neighborhoods among older adults [49]. Other investigators have found that among older adults, individual-level perceptions of social cohesion are positively associated with walking [50]. Similarly, among older adults having a good social network is positively associated with both PA initiation and maintenance [51, 52]. Extending research that has focused on the PA correlates of younger and middle-aged adults [53-55], there is preliminary evidence that individual-level cognitive factors and perceptions of the social environment influence PA engagement among older adults.
Among previous studies examining the role of individual-level and environmental factors on PA among older adults, the majority of research has focused predominantly on White adults [24-27, 32-34, 45, 47, 52]. Although previous interventions have targeted individuallevel factors (e.g., behavioral skills training, self-efficacy) as strategies for promoting PA among young and middleaged African American adults [56, 57], surprisingly little research has addressed the factors that promote PA among older African American adults. Among African American adults, reduced access to facilities, a lack of a safe place to exercise, lack of time, and low motivation are among the most frequently reported barriers to PA [58-62]. Enhanced personal and environmental barriers, coupled with the tendency for PA to decrease with age $[12,13]$, underscores the need to understand the factors that promote PA initiation and maintenance among older African American adults.

Another key limitation of previous studies of PA among older adults is that relatively little is known about the extent to which the impact of individual-level and environmental factors changes across time. For example, among studies of older adults, several studies have indicated that self-efficacy is important for PA initiation and maintenance [24-27, 63-65]; however, numerous experimental studies have failed to find an association between self-efficacy and PA initiation or maintenance [66-68] (for a review see van Stralen and colleagues, 2009 [21]). Relatedly, recent systematic reviews of self-determined motivation for PA [30] and the role of the built environment [46] both concluded that the majority of extant research has used cross-sectional designs and self-reported PA. Furthermore, to date no study has examined how a positive self-concept for PA relates to accelerometry estimated PA over time among older adults. Taken together, there remain many unanswered questions about how individual-level cognitive and social neighborhood factors may impact PA longitudinally in older adults.

The primary aim of this study was to directly compare how individual-level cognitive factors for PA (self-efficacy for PA, self-determined motivation for PA, self-concept for PA) and neighborhood perceptions of social factors for PA (neighborhood satisfaction, neighborhood social life) impact accelerometer-assessed PA across 24-months among older African American adults. The present study uses data collected from participants in the Positive Action for Today's Health (PATH) trial [69-71], which includes measures of self-efficacy for PA, self-determined motivation for PA, self-concept for PA, neighborhood satisfaction, neighborhood social life, and accelerometerassessed MVPA from baseline through 24 months. The hierarchical nature of this data allows us to examine both between- and within-person effects. We hypothesized that between-person mean differences in self-efficacy for PA, 
self-determined motivation for PA, self-concept for PA, neighborhood satisfaction and social life would be positively associated with greater MVPA. Additionally, we hypothesized that the relationship between MVPA and the between-person effects would remain constant across time (i.e., no significant interactions with time). Finally, we examined whether within-person changes in the predictors were associated with changes in MVPA as exploratory analyses.

\section{Methods}

\section{Design and setting}

The PATH study randomized communities to receive an environmental intervention for increasing perceptions of safety and access to neighborhood-based physical activity among African Americans [69-71]. Three communities in South Carolina were selected based on census tract level information and were randomized to receive one of three interventions: a police-patrolledwalking program with a social marketing intervention, a police-patrolled walking program only, or a no-walking general health education program. Although the larger trial led to greater neighborhood trail walking, there were no between-group differences in accelerometerestimates of MVPA in the full intervention community. Measures were collected at baseline, 12, 18, and 24 months. To measure MVPA, participants wore accelerometers for seven consecutive days. Additionally, at each time point participants completed a series of psychosocial measures, including self-concept for PA, self-determined motivation for PA, self-efficacy for PA, neighborhood satisfaction, and neighborhood social life. The study was approved by the Institution Review Board at the University of South Carolina. All participants signed informed consent prior to participating in the study and received monetary compensation in the form of a US \$20 gift card at each assessment period, with the exception of the 24-month assessment when participants received a US $\$ 40$ gift card.

\section{Participants}

Two recruitment strategies were used in the PATH trial. First, participants were recruited via telephone calls and letters from a list of households in specified census tracts in each targeted community provided by the University of South Carolina Survey Laboratory. Of the 1986 households contacted, 1216 were reached, 581 declined, 635 individuals were invited to participate, and 231 enrolled in the study. As a second recruitment method, 203 volunteers were recruited using flyers, ads placed in local newspapers, and posters placed in churches, schools and local businesses [69-71]. Approximately $54 \%$ of the final sample was recruited using the random list of households and 46\% was recruited through volunteer advertisements. The inclusion criteria for the study included: 1) African American (three of four grandparents of African heritage), 2) 18 years or older, 3) had no plans to move in the next two years, 4) had no medical condition that would prevent them from engaging in regular PA, and 5) had controlled blood pressure (systolic $<180 \mathrm{mmHg}$ systolic and diastolic $<110 \mathrm{mmHg}$ ) and blood sugar levels (non-fasting $<300 \mathrm{mg} / \mathrm{dl}$ and fasting $<250 \mathrm{mg} / \mathrm{dl}$ ). Participants were excluded if they indicated that they could not safely participate in moderate PA. A total of 434 adults were enrolled in the study (with age ranging from 18 to 85 and a median age of 51 years). Seventeen participants did not provide accelerometer-assessed MVPA at any of the time points, and were therefore excluded from data analysis. Given that the present study focuses specifically on older adults, we conducted a median split and included data from adults who were 51 years or older, yielding a final sample size of 224. The decision to include adults over the age of 50 is consistent with the inclusion criteria used in systematic reviews of PA among older adults [21].

\section{Data collection and measures Actical accelerometer assessments}

At each time point, Actical devices were used to assess MVPA over seven consecutive days (Mini-Mitter, Bend, OR). Acticals are small electronic devices that assess both intensity and frequency of movement to index daily minutes of light, moderate, and vigorous physical activity. Whereas accelerometers detect movement on uni- and bi-directional planes, Acticals detect movement omnidirectionally, and therefore provide a more sensitive measure of PA [72]. Acticals have acceptable test re-test reliability coefficients for MVPA ranging from 0.85-0.90 [73]. Participants were instructed to wear the Actical on their right hip at all times, excluding sleep and occasions when the Actical could get wet. Activity was categorized as MVPA if counts per minutes were at least 1075, which was based on a calibration study conducted with a sample similar to the PATH trial [74]. MVPA scores index daily minutes of PA.

\section{Self-concept for PA}

Participants completed the 10-item Self Concept and Motivation to Exercise Scale to assess their health selfconcept concerning the importance of increasing PA and motivation to change PA (e.g., "I am the type of person who likes to exercise daily"; "Exercising regularly is a very important part of my everyday life") [75, 76]. Items were answered on a 6-point scale ranging from one (Strongly Disagree) to six (Strongly Agree). The scale demonstrated acceptable reliability at all time points $(\alpha=0.83-0.87)$ and past studies have demonstrated 
construct validity among African American populations $[75,76]$.

\section{Self-determined motivation for PA}

Participants completed a brief 8-item version of the Behavioral Regulation in Exercise Questionnaire assessing their reasons for engaging in exercise (e.g., "I enjoy my exercise sessions"; "I think it's important to make the effort to exercise regularly"; adapted from Mullan and Markland [77]). Items were answered using a 5-point scale ranging from one (Not True of Me) to five (Very True of $m e)$. The scale demonstrated acceptable reliability at all time points $(\alpha=0.72-0.75)$ and past studies have demonstrated construct validity among African American populations [78].

\section{Self-efficacy for PA}

Participants completed the 16-item Self-Efficacy for Exercise Questionnaire to assess their confidence in their ability to exercise when faced with potential barriers (e.g., "I am confident I could exercise over the next 6 months when tired"; "I am confident I could exercise over the next 6 months during bad weather"; adapted from Garcia and King [79]). Items were answered using an 11-point scale ranging from $0 \%$ confident to $100 \%$ confident. The scale demonstrated acceptable reliability at all time points $(\alpha=0.95-0.96)$ and past studies have demonstrated acceptable internal consistency and testretest reliability [79].

\section{Neighborhood satisfaction}

Participants completed the 26-item Neighborhood Environment Walkability Scale [80]. Six items were used to compute the Neighborhood Satisfaction subscale to assess participants' general satisfaction with their neighborhood (e.g., "How satisfied are you with how easy and pleasant it is to walk in your neighborhood?"; "How satisfied are you with how many friends you have in your neighborhood?") Items were answered on a 5-point scale ranging from one (Strongly Dissatisfied) to five (Strongly Satisfied). The scale demonstrated acceptable reliability at all time points $(\alpha=0.78-0.83)$ and past studies have demonstrated good internal consistency and test-retest reliability [80].

\section{Neighborhood social life}

Participants completed 9-items from the Neighborhood Social Interaction scale (adapted from Elliot et al. [81]). Items assessed how often participants had engaged in informal social activities in their neighborhood (e.g., "Stopped and talked with a neighbor"). The scale demonstrated acceptable reliability at all time points $(\alpha=0.80-0.86)$ and past studies have demonstrated acceptable internal consistency [81].

\section{Statistical analyses}

To account for differences in scaling across the five predictors, individual items for each of the five scales were $\mathrm{z}$-scored. The $\mathrm{z}$-scored values for each scale were summed, and then z-scored again. A square root transformation was applied to MVPA to normalize a skewed distribution. Accelerometer data were missing for $4.01 \%$ of participants at baseline and for 19.64-26.34\% at each of the follow-up time points. A compliance criterion of one or more 4-h intervals was used and combined with multiple imputation, a robust technique for accounting for missing data, that is considered appropriate for accelerometry and longitudinal data [82-84]. The MICE package in $\mathrm{R}$ [85] was used to generate 20 imputations (for further discussion of this approach see our previous publication [70]). One imputation was randomly selected for conducting the present analyses.

Multilevel growth modeling [86] was used to account for the hierarchical structure of the data. To explore statistical assumptions associated with multilevel modeling, the residuals of the random effects were examined in the model. Plots of the standardized Level - one studentized residuals against their normal scores showed a linear association, suggesting relative normality and no extreme outliers. Additionally, plots of the residuals against the predicted values of MVPA showed no signs of significant heteroscedacicity.

Each predictor (self-determined motivation for PA, self-efficacy for PA, self-concept for PA, neighborhood satisfaction, and neighborhood social life) was parsed into separate between- and within-person components. Between-person scores were calculated by averaging an individual's score on a predictor across time and withinperson scores were calculated by subtracting each person's score at each time point from his or her personal mean. The slopes for the between-person component indexes the magnitude of the relationship between individuals' mean score on a predictor and their mean level of MVPA. Time was centered such that (baseline $=-1$, 12 months $=0,18$ months $=.5,24$ months $=1)$, such that a 1-unit change in time corresponds to the passage of 1 year. Additionally, the models tested for interactions between time and the between-person mean scores. A non-significant interaction would indicate that the relationship between participant's mean level on a predictor and MVPA remained stable across the 24-month followup period.

To aid convergence, only the intercept and time were permitted to vary as random effects. Age, sex $(0=$ male, 1 = female), baseline body mass index (BMI), and baseline annual income $(0=<\$ 10,000,1=\$ 10,000-24,000$, $2=>\$ 24,000)$ were included as covariates. Additionally, two dummy coded community variables were included as covariates to account for intervention effects from the 
larger trial. Grand-mean centering was applied to age and BMI.

A hierarchical approach was used to analyze the data, such that model one includes only the effects of the covariates and time. Model two includes the addition of the between- and within-person factors. Finally, model three includes the addition of the interaction terms between the between-person factors and time. To examine whether the addition of the between- and within-person factors and the interaction terms significantly contributed to the prediction of MVPA, likelihood ratio tests were conducted to compare the change in the residual between model 1 and 2 , and between model 2 and 3 . By comparing the change in the residual, likelihood ratio tests allows one to examine whether there is a significant increase in the total variance accounted for in a given model.

\section{Results}

\section{Descriptive statistics}

Baseline characteristics of the sample are presented in Table 1. The sample was African American and predominantly female $(68.30 \%)$, obese $\left(M_{\mathrm{BMI}}=32.01, S D=7.52\right)$, ranged in age from 51 to 85 years $(M=63.23, S D=8.74)$, and had a mean annual household income that was less than or equal to $\$ 25,000$.

\section{Correlations}

Table 2 presents the unstandardized means and standard deviations for self-efficacy for PA, self-determined motivation for PA, self-concept for PA, neighborhood social life, neighborhood satisfaction, and MVPA at all time points. Self-concept scores were moderately correlated across all time points with self-determined motivation $(r \mathrm{~s}=0.51-0.64)$, and self-efficacy $(r \mathrm{~s}=0.52-0.59)$, but not at the magnitude of collinearity. Self-concept scores had a small correlation with neighborhood social life $(r s=-0.29-0.09)$ and neighborhood satisfaction ( $r \mathrm{~s}=0.14-0.29)$. All other bivariate correlations between predictors across time points were less than or equal to $r=0.48$.

\section{Model ICCs}

Intercept-only models (i.e., no predictors) were conducted for all study variables to examine the degree of variance attributable to the within- and between-person levels. From these models, intraclass correlation coefficients (ICC) were computed, which provide an index of the proportion of variance associated with betweenperson differences. The ICCs indicated that between 43.91 to $53.62 \%$ of the variance was attributable to between-person differences. Thus, the use of multi-level modeling was deemed appropriate [87].
Table 1 Baseline characteristics of path sample $(N=224)$

\begin{tabular}{|c|c|}
\hline Valiable & \\
\hline \multicolumn{2}{|l|}{ Gender } \\
\hline Male & 71 \\
\hline Female & 153 \\
\hline \multicolumn{2}{|l|}{ Age (years) } \\
\hline Mean (SD) & $63.23(8.74)$ \\
\hline $50-55$ & 52 \\
\hline $56-60$ & 44 \\
\hline $61-65$ & 46 \\
\hline $66-70$ & 27 \\
\hline $71-75$ & 33 \\
\hline $76-85$ & 22 \\
\hline \multicolumn{2}{|l|}{ Marital status } \\
\hline Married & 63 \\
\hline Separated & 27 \\
\hline Divorced & 31 \\
\hline Widowed & 75 \\
\hline Never married & 24 \\
\hline Unmarried couple & 4 \\
\hline \multicolumn{2}{|l|}{ Employment } \\
\hline Working & 72 \\
\hline Laid off/unemployed & 28 \\
\hline Retired & 97 \\
\hline Disabled & 22 \\
\hline Homemaker & 4 \\
\hline Student & 1 \\
\hline \multicolumn{2}{|l|}{ Education } \\
\hline$<\mathrm{HS}$ degree & 67 \\
\hline HS degree/GED & 78 \\
\hline Some college/technical training & 45 \\
\hline College degree & 12 \\
\hline Graduate/professional degree & 22 \\
\hline \multicolumn{2}{|l|}{ Income } \\
\hline$<$ US\$10,000 & 54 \\
\hline US\$10,000-24,000 & 88 \\
\hline$>$ US\$24,000 & 82 \\
\hline \multicolumn{2}{|l|}{ BMl } \\
\hline Mean (SD) & $32.01(7.52)$ \\
\hline$<25$ & 32 \\
\hline $25-<30$ & 69 \\
\hline$>30$ & 123 \\
\hline
\end{tabular}

\section{Between and within-person effects on MVPA}

A hierarchical approach was used to examine whether the inclusion of the covariates (model 1), the between and within-person effects (model 2), and the time*between- 
Table 2 Means standard deviations for the individual-level cognitive and social environment factors across time

\begin{tabular}{|c|c|c|c|c|c|c|c|c|}
\hline \multirow[b]{2}{*}{ Valiables } & \multicolumn{2}{|c|}{ Baseline } & \multicolumn{2}{|c|}{12 months } & \multicolumn{2}{|c|}{18 months } & \multicolumn{2}{|c|}{24 months } \\
\hline & $\bar{M}$ & $S D$ & $\bar{M}$ & $S D$ & $\bar{M}$ & $S D$ & $\bar{M}$ & SD \\
\hline Self-Determined Motivation for PA & 3.39 & 0.81 & 3.41 & 0.77 & 3.35 & 0.28 & 3.38 & 0.28 \\
\hline Self-Concept for PA & 4.20 & 0.98 & 4.11 & 0.96 & 4.06 & 0.96 & 3.95 & 1.00 \\
\hline Self-Efficacy for PA & 61.78 & 22.54 & 56.63 & 23.39 & 53.75 & 22.28 & 50.32 & 24.20 \\
\hline Neighborhood Satisfaction & 3.84 & 0.37 & 3.69 & 0.85 & 3.76 & 0.83 & 3.87 & 0.75 \\
\hline Neighborhood Social Life & 9.13 & 5.85 & 9.76 & 5.78 & 9.81 & 6.47 & 10.32 & 7.29 \\
\hline MVPA & 17.06 & 26.60 & 24.48 & 32.14 & 25.38 & 41.54 & 17.63 & 30.63 \\
\hline
\end{tabular}

Raw means are presented in Table 2. Analyses were conducted on z-scored scale values and square root transformed MVPA

person interaction effects (model 3) improved the prediction of MVPA. Models $1-3$ yielded $R^{2}$ values of 0.153 , 0.240 , and 0.249 , respectively. To examine whether the addition of the between- and within-person factors (model 2) and the interaction terms (model 3) significantly contributed to the prediction of MVPA, likelihood ratio tests were conducted to compare the change in the residual between the models. The inclusion of the between- and withinperson factors in model 2 yielded a significant reduction in the -2 Residual Log Likelihood relative to model $1, \chi^{2}$ $(1)=20.77, p<0.001$. The inclusion of the interaction terms yielded a small and non-significant reduction in the residual relative to model $2, \chi^{2}(1)=0.29, p=0.59$. The results of the likelihood ratio tests revealed that including the individual-level cognitive and environmental factors significantly improved the prediction of MVPA relative to a covariates-only model. Although collectively the inclusion of the between-person"time interactions did not significantly improve the prediction of MVPA, we present the full results of model 3 to examine whether any of the individual between-person*time interaction effects significantly predict MVPA (see Table 3).

As seen in Table 3 , being younger in age ${ }^{1}$ and being male were associated with greater levels of MVPA. Additionally, being assigned to the full intervention community (relative to the control community) was associated with greater MVPA. There was no significant fixed effect of time, income, or BMI. At the withinperson level, only changes in neighborhood social life and changes in self-concept predicted increased MVPA. At the between-person level, self-concept and neighborhood social life predicted greater MVPA, whereas neighborhood satisfaction predicted lower MVPA. Among the between-person effects, only average social life was moderated by time. The positive sign of this interaction indicates that people with a higher average neighborhood social life engaged in greater MVPA than people with a lower social life, with the strength of this association increasing across time. Conversely, the impact of average neighborhood satisfaction and average self-concept remained relatively stable across time, as time did not significantly moderate the effect of these factors. At the within-person level, neighborhood social life and selfconcept predicted increased MVPA, indicating that positive increases in self-concept and neighborhood social life were associated with increased MVPA.

\section{Discussion}

The results of this study indicated that that people with a higher average self-concept for PA engaged in greater MVPA than people with a lower average self-concept for PA. Furthermore, people with more positive perceptions of their neighborhood social life engaged in greater MVPA than people with less positive perceptions. Additionally, changes in perceptions of one's neighborhood social life and changes in one's self-concept for PA were associated with increased MVPA. Thus, when compared directly with other individual-level cognitive factors (self-efficacy for PA, self-determined motivation for PA), having a positive self-concept for PA and a positive social life were significant predictors of longitudinal MVPA among older African American adults.

In contrast to previous studies, which have found positive associations between PA and self-determined motivation [32-34] and self-efficacy [24-27], the present study demonstrated that being relatively high or low on these factors did not predict MVPA across time in older African Americans. Additionally, in the present study we did not observe any significant within-person effects of self-determined motivation or self-efficacy on MVPA. Previous studies of older adults have indicated a positive association between self-efficacy and PA through crosssectional designs [26], but longitudinal studies have found evidence of both growth [88] and decline [89] of self-efficacy across time. Similarly, the majority of past studies of self-determined motivation and PA have used cross-sectional designs [30]. Changes in personal and environmental barriers across time may differentially influence one's perceived competence and motivation for engaging in PA; as a result, self-efficacy and selfdetermined motivation for PA may be relatively less impactful on long-term PA maintenance. Alternatively, to the extent that one's self-concept helps to organize and guide one's actions [90], it follows that a positive self- 
Table 3 Multilevel growth models predicting MVPA

\begin{tabular}{|c|c|c|c|c|c|c|}
\hline & & & & & Lower & Upper \\
\hline Predictors & $b$ & SE & $t$ & $p$ & $95 \% \mathrm{Cl}$ & $95 \% \mathrm{Cl}$ \\
\hline \multicolumn{7}{|l|}{ Fixed effects } \\
\hline Intercept & 4.171 & 0.329 & 12.693 & $<.001$ & 3.526 & 4.816 \\
\hline Time & 0.115 & 0.102 & 1.132 & 0.258 & -0.084 & 0.314 \\
\hline Body mass index & -0.014 & 0.016 & -0.926 & 0.355 & -0.045 & 0.016 \\
\hline Age & -0.0947 & 0.014 & -6.807 & $<.001$ & -0.121 & -0.067 \\
\hline Female & -0.983 & 0.271 & -3.622 & $<.001$ & -1.518 & -0.448 \\
\hline Income & -0.117 & 0.158 & -0.740 & 0.460 & -0.429 & 0.195 \\
\hline Community Dummy Code 1 (Walking Only) & 0.425 & 0.291 & 1.461 & 0.146 & -0.148 & 0.998 \\
\hline Community Dummy Code 2 (Full Intervention) & 0.602 & 0.285 & 2.115 & 0.036 & 0.041 & 1.163 \\
\hline \multicolumn{7}{|l|}{ Within-person change } \\
\hline Self-Determined Motivation for PA & -0.147 & 0.126 & -1.165 & 0.245 & -0.395 & 0.101 \\
\hline Self-Efficacy for PA & -0.092 & 0.121 & -0.759 & 0.448 & -0.329 & 0.146 \\
\hline Self-Concept for PA & 0.294 & 0.145 & 2.026 & 0.043 & 0.009 & 0.579 \\
\hline Neighborhood Satisfaction & -0.212 & 0.117 & -1.820 & 0.069 & -0.442 & 0.017 \\
\hline Neighborhood Social Life & 0.270 & 0.113 & 2.392 & 0.017 & 0.048 & 0.492 \\
\hline \multicolumn{7}{|l|}{ Between-person difference } \\
\hline Mean Self-Determined Motivation for PA & -0.151 & 0.231 & -0.655 & 0.513 & -0.606 & 0.303 \\
\hline Mean Self-Efficacy for PA & -0.003 & 0.199 & -0.017 & 0.987 & -0.395 & 0.388 \\
\hline Mean Self-Concept for PA & 0.872 & 0.239 & 3.644 & $<.001$ & 0.400 & 1.344 \\
\hline Mean neighborhood Satisfaction & -0.422 & 0.172 & -2.451 & 0.015 & -0.762 & -0.083 \\
\hline Mean neighborhood Social Life & 0.826 & 0.176 & 4.702 & $<.001$ & 0.479 & 1.172 \\
\hline \multicolumn{7}{|l|}{ Between-person interactions } \\
\hline Time $\cdot$ Mean Self-Determined for PA & -0.345 & 0.188 & -1.839 & 0.066 & -0.714 & 0.023 \\
\hline Time $\cdot$ Mean Self-Efficacy for PA & -0.059 & 0.165 & -0.361 & 0.718 & -0.382 & 0.264 \\
\hline Time $\cdot$ Mean Self-Concept for PA & 0.213 & 0.201 & 1.057 & 0.291 & -0.183 & 0.608 \\
\hline Time $\cdot$ Neighborhood Satisfaction & 0.084 & 0.142 & 0.593 & 0.554 & -0.194 & 0.362 \\
\hline Time •Neighborhood Social Life & 0.361 & 0.147 & 2.456 & 0.014 & 0.072 & 0.649 \\
\hline \multicolumn{7}{|l|}{ Random effects } \\
\hline Intercept & 1.317 & & & & 1.223 & 1.545 \\
\hline Time & 0.215 & & & & 0.068 & 0.682 \\
\hline Residual & 2.118 & & & & & \\
\hline
\end{tabular}

Model $R^{2}=0.49$

concept for PA will be a relatively robust predictor of PA maintenance. Taken together, the present findings underscore the importance of complementing crosssectional studies with longitudinal designs to clarify how the relationship between individual-level cognitive factors and PA maintenance change across time among older adults.

In the present study we found that among the three communities included in the PATH trial, a more positive neighborhood social life predicted greater MVPA across 24 months. In a previous study from the PATH trial [91], we found that that across 12 months participants in the full intervention community of the PATH trial engaged in more trail walking outside of their neighborhood when perceptions of neighborhood social life were low. Although this finding may appear somewhat inconsistent with the present results, the present study varies on a number of critical dimensions from the previous study [91], including differences in PA intensity (walking vs. MVPA), PA measurement (self-report vs. accelerometry estimates), and measurement length (12 months vs 24 months). Taken together, we conclude that when perceptions of the neighborhood social life are low people are more likely to pursue opportunities for PA outside of 
their immediate neighborhood (such as joining a walking group on a community trial), but overall when neighborhood social life is high greater adherence to MVPA may occur within the context of one's neighborhood.

Surprisingly, in the present study we found that greater average neighborhood satisfaction predicted lower MVPA. Whereas past studies have found positive effects of neighborhood satisfaction on PA among older adults [92], such studies have tended to be cross-sectional and have focused on older White adults. Importantly, past studies have documented mixed results regarding the relationship between specific aspects of the environment and physical activity among older adults [93]. To further clarify the relationship between neighborhood satisfaction, social life, and MVPA, future research should examine how different intensities of PA, both within and outside of one's immediate neighborhood, varies across racial, ethnic, and socio-economic status groups.

The present findings highlight a positive neighborhood social life as a key predictor of PA among older African Americans. Much of the extant literature on PA among older adults has focused on the role of the physical environment, including factors such as perceptions of safety, neighborhood walkability, and proximity of recreational facilities [44-46, 94]. Relatively fewer studies have examined the role of the social environment among older adults, with much of the previous research focusing on other aspects of the social environment, including the role of social support $[26,47,95,96]$, social cohesion $[49,50]$ and neighborhood or social involvement $[97,98]$ as predictors of PA. Building on previous prospective work of social environmental factors [99], and cross-sectional studies [26, 48, 49, 95-98], the present findings provide further evidence for the longitudinal impact of a positive neighborhood social life on objectively-assessed PA among older adults.

Future research is needed to test how positive changes in self-concept and neighborhood social life can be further integrated into PA interventions. For example, past studies have found that helping people to make deliberate connections between their values and a target behavior is an effective behavior change strategy for adoption of health behaviors [100], with past studies finding positive effects of such programs among African Americans [56]. Furthermore, there is evidence that focusing on one's values promotes an expanded sense of one's selfconcept [101]. Future research could build upon this approach by examining how focusing on one's core values could be used to facilitate positive changes in one's selfconcept for PA for long-term change and maintenance. Additionally, future interventions should consider how to develop community-based programs to promote social support, cohesion, and positive social opportunities for engaging in PA within neighborhoods.
By incorporating a longitudinal design, an objectivelyassessed measure of PA, and a sample of older African American adults, the present study addresses some of the key methodological limitations of past research. Furthermore, relatively few studies have examined how individual-level cognitive factors and neighborhood perceptions impact longitudinal MVPA among predominantly older obese African American adults. In the United States, African American adults have the highest rate of obesity [102], and a higher rate of physical inactivity relative to White adults [103, 104]. Interestingly, whereas our previous work tested for intervention effects among the full PATH trial sample $(N=417$, ages $18-85)$ [70], by focusing specifically on older adults in the PATH trial, the present study revealed a treatment effect that was not reported in our previous research. These findings suggest that the full intervention was particularly beneficial for increasing MVPA among relatively older participants. Taken together, the present results provide valuable insight into the individual and social environmental factors that predict longitudinal MVPA among older African Americans in the PATH trial.

There are several limitations to the present study that should be acknowledged. One limitation of the present research is that the generalizability of the present findings beyond African Americans remains unclear. Future research is needed to confirm that the positive effect of self-concept for PA and neighborhood social life generalize to other racial and ethnic groups of older adults. Another limitation of the present research is that the present analyses were conducted on a single imputation, which may yield less reliable estimates than a combined multiple imputation approach. A third limitation is that the trial recruited a mixture of randomly selected and volunteer participants. By including volunteer participants the trial may have inadvertently selected some participants with a higher level of motivation.

\section{Conclusions}

This study expands on past research by demonstrating that among older African American adults, those with a higher average positive self-concept for PA engaged in greater MVPA than those with a low average selfconcept. This is one of the first studies, to date, to examine how self-concept for PA relates to longitudinal objective assessments of MVPA among older adults. Additionally, positive increases in one's perceived neighborhood social life and in one's self-concept for PA were associated with increases in MVPA over time. Future interventions should consider how positive changes in self-concept and the neighborhood social environment can be further integrated into PA interventions in older at-risk adults. 


\section{Endnote}

${ }^{1}$ To examine further how the observed effects were related to age, we ran additional analyses to test whether age moderated any of the between-person effects. At the between-person level, only average self-determined motivation was moderated by age, $B=-0.060, S E=0.026$, $p=0.026,95 \% C I=-0.112,-0.007$.

\section{Abbreviations}

BMI: Body mass index; ICC: Intraclass correlation coefficients; MVPA: Moderate to vigorous physical activity; PA: Physical activity

\section{Acknowledgements}

We thank the members of the Obesity Research Group at the University of South Carolina.

\section{Funding}

This article was supported by grants (R01 DK067615, R01 DK067615-03S1A1) funded by the National Institutes of Diabetes, Digestive, and Kidney Diseases, and a grant (R01 HD072153) funded by the National Institutes of Child Health and Human Development awarded to Dawn K. Wilson, Ph.D.

\section{Availability of data and materials}

The datasets used during the current study is available from the corresponding author on reasonable request.

\section{Authors' contributions}

DK and $\mathrm{VH}$ contributed to the overall design and implementation of the trial. $\mathrm{AS}, \mathrm{DK}$, and $\mathrm{VH}$ contributed to the conception of the planned analyses. AS conducted the analyses and drafted the first version of the article. All authors critically commented and revised text and approved the submission of the final version.

\section{Competing interests}

The authors declare that they have no competing interests.

\section{Consent for publication}

Not applicable.

\section{Ethics approval and consent to participate}

The study was approved by the Institution Review Board at the University of South Carolina. All participants signed informed consent and received monetary compensation for their participation.

\section{Author details}

${ }^{1}$ Department of Psychology, University of South Carolina, 1233 Washington Street, 9th Floor, Columbia, SC 29208, USA. '2Department of Individual, Family, and Community Education, University of New Mexico, Albuquerque, NM 87131, USA.

Received: 16 November 2016 Accepted: 11 May 2017 Published online: 22 May 2017

\section{References}

1. Agency for Healthcare Research and Quality. Centers for Disease Control and Prevention. Physical activity and older Americans. Benefits and strategies. 2008. https:/innovations.ahrq.gov/qualitytools/physical-activity-and-older-americansbenefits-and-strategies. Accessed 20 Oct 2016

2. U.S. Department of Health and Human Services. 2008 physical activity guidelines for Americans. https://health.gov/paguidelines/guidelines/ summary.aspx. Accessed 20 Dec 2016.

3. Chodzko-Zajko WJ, Wojtek J. Exercise and physical activity for older adults. Kinesiol Rev. 2014;3:101-6. doi:10.1123/kr.2014-0043.

4. Elsawy B, Higgins KE. Physical activity guidelines for older adults. Am Fam Physician. 2010;81:55-9.

5. Wen CP, Wai JP, Tsai MK, Yang YC, Cheng TY, Lee MC, Chan HT, Tsao CK, Tsai SP, Wu X. Minimum amount of physical activity for reduced mortality and extended life expectancy: a prospective cohort study. Lancet. 2011;378:1244-53.
6. Lee $Y$, Park K. Health practices that predict recovery from functional limitations in older adults. Am J Prev Med. 2006;31:25-31. doi:10.1016/ j.amepre.2006.03.018.

7. Sjösten N, Kivelä S-L. The effects of physical exercise on depressive symptoms among the aged: a systematic review. Int J Geriatr Psychiatry. 2006;21:410-8. doi:10.1002/gps.1494.

8. Angevaren M, Aufdemkampe G, Verhaar H, Aleman A, Vanhees L. Physical activity and enhanced fitness to improve cognitive function in older people without known cognitive impairment. Cochrane Database Syst Rev. 2008:1-73. doi:10.1002/14651858.CD005381.

9. Colcombe S, Kramer AF. Fitness effects on the cognitive function of older adults: a meta-analytic study. Psychol Sci. 2003;14:125-30. doi:10.1111/ 1467-9280.t01-1-01430.

10. Erickson Kl, Voss MW, Prakash RS, Basak C, Szabo A, Chaddock L, Kim JS, Heo S, Alves H, White SM, Wojcicki TR. Exercise training increases size of hippocampus and improves memory. Proc Natl Acad Sci. 2011;108:3017-22. doi:10.1073/pnas.1015950108.

11. Spiduso WW, Cronin DL. Exercise dose-response effects on quality of life and independent living in older adults. Med Sci Sports Exerc. 2001;33:S598-608. doi:10.1097/00005768-200106001-00028.

12. Davis MG, Fox KR. Physical activity patterns assessed by accelerometry in older people. Eur J Appl Physiol. 2007;100:581-9. doi:10.1007/s00421006-0320-8.

13. Rutten A, Abu-Omar K. Prevalence of physical activity in the European Union. Soc Prev Med. 2004;49:281-9. doi:10.1007/s00038-004-3100-4.

14. Watson KB, Carlson SA, Gunn JP, Galuska DA, O'Connor A, Greenlund KJ, Fulton JE. Physical Inactivity Among Adults Aged 50 Years and Older — United States, 2014. Morb Mortal Wkly Rep. 2016;65:954-8. doi:10.15585/mmwr.mm6536a3.

15. Sun F, Norman IJ, While AE. Physical activity in older people: a systematic review. BMC Public Health. 2013:13:1-17. doi:10.1186/1471-2458-13-449.

16. Center for Disease Control and Prevention. State Indicator Report on Physical Activity. 2014. https://www.cdc.gov/physicalactivity/downloads/pa_ state_indicator_report_2014.pdf Accessed 20 Oct 2016.

17. Ward BW, Clark TC, Nugent CN, Schiller JS. Early release of selected estimates based on data from the 2015 National Health Interview Survey. National Center for Health Statistics 2016. https://www.cdc.gov/nchs/data/ nhis/earlyrelease/earlyrelease201605.pdf Accessed 20 Oct 2016.

18. Centers for Disease Control and Prevention. CDC Health Disparities and Inequalities Report - United States, 2013. MMWR: Morb Mortal Wkly Rep. 2013;62:1-186

19. Van Lenthe FJ, Martikainen P, Mackenbach JP. Neighbourhood inequalities in health and health-related behaviour: results of selective migration? Health Place. 2007;13:123-37. doi:10.1016/j.healthplace.2005.09.013.

20. King AC. Interventions to promote physical activity by older adults. J Gerontol Ser A Biol Med Sci. 2001;56:36-46. doi:10.1093/gerona/ 56.suppl_2.36.

21. van Stralen MM, De Vries H, Mudde AN, Bolman C, Lechner L. Determinants of initiation and maintenance of physical activity among older adults: a literature review. Health Psychol Rev. 2009:3:147-207. doi:10.1080/ 17437190903229462

22. Bandura A. Self-efficacy: toward a unifying theory of behavioral change. Psychol Rev. 1977:84:191-215. doi:10.1037/0033-295X.84.2.191.

23. Bandura A. Social foundations of thought and action: a social cognitive theory. Prentice-Hall, Inc: New York, NY; 1986.

24. McAuley E. Self-efficacy and the maintenance of exercise participation in older adults. J Behav Med. 1993;16:103-13. doi:10.1007/BF00844757.

25. McAuley E, Lox C, Duncan TE. Long-term maintenance of exercise, self-efficacy, and physiological change in older adults. J Gerontol. 1993;48:218-24. doi:10.1093/geronj/48.4.P218.

26. Booth ML, Owen N, Bauman A, Clavisi O, Leslie E. Social-cognitive and perceived environment influences associated with physical activity in older Australians. Prev Med. 2000;31:15-22. doi:10.1006/pmed.2000.0661.

27. McAuley E, Morris KS, Motl RW, Hu L, Konopack JF, Elavsky S. Long-term follow-up of physical activity behavior in older adults. Health Psychol. 2007;26:375-80. doi:10.1037/0278-6133.26.3.375.

28. Ryan RM, Deci EL. Self-determination theory and the facilitation of intrinsic motivation, social development, and well-being. Am Psychol. 2000;55:68-78. doi:10.1037//0003-066x.55.1.68

29. Ryan RR, Williams GC, Patrick H, Deci EL. Self-determination theory and physical activity: the dynamics of motivation in development and wellness. Hell J Psychol. 2009;6:107-24. 
30. Teixeira PJ, Carraça EV, Markland D, Silva MN, Ryan RM. Exercise, physical activity, and self-determination theory: a systematic review. Int J Behavl Nutr Phys Act. 2012;9:1-30. doi:10.1186/1479-5868-9-78.

31. Stewart AL, Verboncoeur CJ, McLellan BY, Gillis DE, Rush S, Mills KM King AC, Ritter P, Brown BW, Bortz WM. Physical activity outcomes of CHAMPS II a physical activity promotion program for older adults. J Gerontol Ser A Biol Med Sci. 2001;56:M465-70. doi:10.1093/gerona/56.8.M465.

32. Milne HM, Wallman KE, Guilfoyle A, Gordon S, Courneya KS. Self-determination theory and physical activity among breast cancer survivors. J Sport Exerc Psychol. 2008;30:23-38. doi:10.1123/jsep.30.1.23.

33. Hurkmans EJ, Maes S, De Gucht V, Knittle K, Peeters AJ, Ronday HK, Vliet Vlieland TPM. Motivation as a determinant of physical activity in patients with rheumatoid arthritis. Arthritis Care Res. 2010;62:371-7. doi:10.1002/acr.20106.

34. Russell KL, Bray SR. Self-determined motivation predicts independent, home-based exercise following cardiac rehabilitation. Rehabil Psychol. 2009:54:150-6. doi:10.1037/a0015595.

35. Stets JE, Burke PJ. Identity theory and social Identity theory. Soc Psychol Q. 2000;63:224-37.

36. Marsh HW, Papaioannou A, Theodorakis Y. Causal ordering of physical self-concept and exercise behavior: reciprocal effects model and the influence of physical education teachers. Health Psychol. 2006;25:316-28. doi:10.1037/0278-6133.25.3.316.

37. Marsh HW, Gerlach E, Trautwein U, Lüdtke O, Brettschneider WD. Longitudinal study of preadolescent sport self-concept and performance: reciprocal effects and causal ordering. Child Dev. 2007;78:1640-56. doi:10.1111/j.1467-8624.2007.01094.x.

38. Wichstrøm L, Kvalem IL. Predictors of growth and decline in leisure time physical activity from adolescence to adulthood. Health Psychol. 2013:32:775-584. doi:10.1037/a0029465.

39. Lemoyne J, Valois P, Guay F. Physical self-concept and participation in physical activity in college students. Med Sci Sports Exerc. 2015;47:142-50. doi: $10.1249 / \mathrm{mss} .0000000000000378$.

40. Markus HR, Herzog AR. The role of the self-concept in aging. In: Warner Schaie K, editor. Annual review of gerontology and geriatrics. New York, NY: Springer Publishing Company; 1991. p. 110-43.

41. Atchley RC. Continuity theory and the evolution of activity in later adulthood. In: Kelly JR, editor. Activity and aging: staying involved in later adulthood. Newbury Park, CA: Sage Publications; 1993. p. 5-16.

42. Mannell RC. High-investment activity and life satisfaction among older adults: committed, serious leisure, and flow activities. In: Kelly JR, editor. Activity and aging: staying involved in later adulthood. Newbury Park, CA: Sage Publications; 1993. p. 123-45.

43. Cross S, Markus H. Possible selves across the life span. Hum Dev. 1991:34:230-55. doi:10.1159/000277058.

44. King AC, Castro C, Wilcox S, Eyler AA, Sallis JF, Brownson RC. Personal and environmental factors associated with physical inactivity among different racial-ethnic groups of U.S. middle-aged and older-aged women. Health Psychol. 2000;19:354-64. doi:10.1037//0278-6133.19.4.354.

45. King WC, Brach JS, Belle S, Killingsworth R, Fenton M, Kriska AM. The relationship between convenience of destinations and walking levels in older women. Am J Health Promot. 2003;18:74-82. doi:10.4278/ 0890-1171-18.1.74

46. Kerr J, Rosenberg D, Frank L. The role of the built environment in healthy aging: community design, physical activity, and health among older adults. J Plan Lit. 2012;27:43-60. doi:10.1177/0885412211415283.

47. Carlson JA, Sallis JF, Conway TL, Saelens BE, Frank LD, Kerr J, Cain KL, King AC. Interactions between psychosocial and built environment factors in explaining older adults' physical activity. Prev Med. 2012;54:68-73. doi:10.1016/j.ypmed.2011.10.004.

48. Sampson RJ, Raudenbush SW, Earls F. Neighborhoods and violent crime: a multilevel study of collective efficacy. Science. 1997;277:918-24. doi:10.1126/science.277.5328.918.

49. Fisher KJ, Li F. Neighborhood-level influences on physical activity among older adults: a multilevel analysis. J Aging Physc Act. 2004;12:45-63. doi:10.1123/japa.12.1.45.

50. Mendes De Leon CF, Cagney KA, Bienias JL, Barnes LL, Skarupski KA, Scherr PA, Evans DA. Neighborhood social cohesion and disorder in relation to walking in community-dwelling older adults: a multi-level analysis. J Aging Heal. 2009;21:155-71. doi:10.1177/0898264308328650.
51. Barrera M, Toobert DJ, Angell KL, Glasgow RE, MacKinnon DP. Social support and social-ecological resources as mediators of lifestyle intervention effects for type 2 diabetes. J Health Psychol. 2006;11:483-95.

52. Burton LC, Shapiro S, German PS. Determinants of physical activity initiation and maintenance among community-dwelling older persons. Prev Med. 1999:29:422-30

53. McNeill LH, Kreuter MW, Subramanian SV. Social environment and physical activity: a review of concepts and evidence. Soc Sci Med. 2006;63:1011-22. doi:10.1016/j.socscimed.2006.03.012.

54. Trost SG, Owen N, Bauman AE, Sallis JF, Brown W. Correlates of adults ' participation in physical activity : review and update. Med Sci Sport Exerc. 2002;34:1996-2001. doi:10.1249/01.MSS.0000038974.76900.92.

55. Giles-Corti B, Timperio A, Bull F, Pikora T. Understanding physical activity environmental correlates: increased specificity for ecological models. Exerc Sport Sci Rev. 2005:33:175-81.

56. Resnicow K, Jackson A, Blissett D, Wang T, McCarty F, Rahotep S, Periasamy S. Results of the healthy body healthy spirit trial. Health Psychol. 2005;24:339-48. doi:10.1037/0278-6133.24.4.339.

57. Parra-Medina D, Wilcox S, Salinas J, Addy C, Fore E, Poston M, Wilson DK. Results of the heart healthy and ethnically relevant lifestyle trial: a cardiovascular risk reduction intervention for African American women attending community health centers. Am J Public Health. 2011;101:1914-21. doi:10.2105/AJPH.2011.300151.

58. Powell LM, Slater S, Chaloupka FJ, Harper D. Availability of physical activity-related facilities and neighborhood demographic and socioeconomic characteristics: a national study. Am J Public Health. 2006;96:1676-80. doi:10.2105/AJPH.2005.065573.

59. Joseph RP, Ainsworth BE, Keller C, Dodgson JE. Barriers to physical activity among African American women: an integrative review of the literature. Women Health. 2015:55:679-99. doi:10.1080/03630242.2015.1039184.

60. King AC, Castro C, Wilcox S, Eyler AA, Sallis JF, Brownson RC. Personal and environmental factors associated with physical inactivity among different racial-ethnic groups of US middle-aged and older-aged women. Health Psychol. 2000;19:354-64. doi:10.1037/0278-6133.19.4.354.

61. Bopp M, Lattimore D, Wilcox S, Laken M, McClorin L, Swinton R, Gethers O, Bryant D. Understanding physical activity participation in members of an African American church: a qualitative study. Health Educ Res. 2007;22:815-26. doi:10.1093/her/cyl149.

62. Doldren MA, Webb FJ. Facilitators of and barriers to healthy eating and physical activity for black women: a focus group study in Florida. USA Crit Public Health. 2013;23:32-8. doi:10.1080/09581596.2012.753407.

63. Cheung C, Wyman J, Gross C, Peters J, Findorff M, Stock H. Exercise behavior in older adults. A test of the transtheoretical model. J Aging Phys. Activ. 2007;15:103-18. doi:10.1123/japa.15.1.103.

64. Duncan TE, McAuley E. Social support and efficacy cognitions in exercise adherence: a latent growth curve analysis. J Behav Med. 1993;16:199-218. doi:10.1007/bf00844893.

65. Oman RF, King AC. Predicting the adoption and maintenance of exercise participation using self-efficacy and previous exercise participation rates. Am J Health Promot. 1998;12:154-61. doi:10.4278/0890-1171-12.3.154.

66. Kelley K, Abraham C. RCT of a theory-based intervention promoting healthy eating and physical activity amongst out-patients older than 65 years. Soc Sci Med. 2004;59:787-97.

67. Pinto BM, Lynn H, Marcus BH, DePue J, Goldstein MG. Physician-based activity counseling: intervention effects on mediators of motivational readiness for physical activity. Ann Behav Med. 2001 Feb 1;23(1):2-10.

68. Burke V, Beilin L, Cutt H, Mansou J, Mori T. Moderators and mediators of behaviour change in a lifestyle program for treated hypertensives: A randomized controlled.trial (ADAPT). Health Educ Res. 2007;B:583-91. doi:10.1093/her/cym047.

69. Wilson DK, Trumpeter NN, St., George SM, Coulon SM, Griffin S, lee van Horn M, Lawman HG, Wandersman a, Egan B, Forthofer M, Goodlett BD, Kitzman-Ulrich $\mathrm{H}$, Gadson B. An overview of the "positive action for Today's health" (PATH) trial for increasing walking in low income, ethnic minority communities. Contemp Clin Trials. 2010;31:624-33. doi:10.1016/j.cct.2010.08.009.

70. Wilson DK, Van Horn ML, Siceloff ER, Alia KA, St. George SM, Lawman HG, Trumpeter NN, Coulon SM, Griffin SF, Wandersman A, Egan B, Colabianchi N, Forthofer M, Gadson B. The results of the Positive action for Today's health (PATH) trial for increasing walking and physical activity in underserved African-American communities. Ann Behav Med. 2015:49:398-410. doi:10.1007/s12160-014-9664-1. 
71. Coulon SM, Wilson DK, Griffin S, St. George SM, Alia KA, Trumpeter NN, Wandersman AK, Forthofer M, Robinson S, Gadson B. Formative process evaluation for implementing a social marketing intervention to increase walking among African Americans in the positive action for today's health trial. Am J Public Health. 2012;102:2315-21. doi:10.2105/AJPH.2012.300758.

72. Esliger DW, Tremblay MS. Technical reliability assessment of three accelerometer models in a mechanical setup. Med Sci Sports Exerc. 2006:38:2173-81. doi:10.1249/01.mss.0000239394.55461.08.

73. Kayes NM, Schluter PJ, McPherson KM, Leete M, Mawston G, Taylor D. Exploring actical accelerometers as an objective measure of physical activity in people with multiple sclerosis. Arch Phys Med Rehabil. 2009;90:594-601. doi:10.1016/j.apmr.2008.10.012.

74. Trumpeter NN, Lawman HG, Wilson DK, Pate RR, Van Horn M.L, Tate AK. Accelerometry cut points for physical activity in underserved African Americans. Int J Behavl Nutr Phys Act 2012;9:1-7. doi: 10.1186/1479-5868-9-73.

75. Wilson DK, Friend R, Teasley N, Green S, Reaves IL, Sica DA. Motivational versus social cognitive interventions for promoting fruit and vegetable intake and physical activity in African American adolescents. Ann Behav Med. 2002;2:310-9. doi:10.1037/e315172004-001.

76. Wilson D, Evan A, Williams J, Mixon G, Sirad J, Pate R. A preliminary test of a student-centered intervention on increasing physical activity in underserved adolescents. Ann Behav Med. 2005;30:119-24. doi:10.1207/s15324796abm3002_4.

77. Mullan E, Markland D, Ingledew DK. A graded conceptualisation of self-determination in the regulation of exercise behaviour: development of a measure using confirmatory factor analytic procedures. Pers Individ Dif. 1997;23:745-52

78. George SM, Wilson DK, Lawman HG, Van Horn ML. Weight status as a moderator of the relationship between motivation, emotional social support, and physical activity in underserved adolescents. J Ped Psychol. 2013;38:387-97. doi:10.1093/jpepsy/jss178.

79. Garcia AW, King AC. Predicting long-term adherence to aerobic exercise: a comparison of two models. J Exerc Sports Psychol. 1991;13:394-410. doi:10.1123/jsep.13.4.394

80. Saelens BE, Sallis JF, Black JB, Chen D. Neighborhood-based differences in physical activity: an environment scale evaluation. Am J Public Health. 2003;93:1552-8. doi:10.2105/ajph.93.9.1552.

81. Elliott DS, Wilson WJ, Huizinga D, Sampson RJ, Elliott A, Rankin B. The effects of neighborhood disadvantage on adolescent development. J Res Crime Delinq. 1996;33:389-426. doi:10.1177/0022427896033004002.

82. Catellier DJ, Hannan PJ, Murray DM, Addy CL, Conway TL, Yang S, Rice JC. Imputation of missing data when measuring physical activity by accelerometry. Med Sci Sports Exerc. 2005;37:S555-62. doi:10.1249/01.mss. 0000185651.59486 .4 e.

83. Enders CK. Analyzing longitudinal data with missing values. Rehabil Psychol. 2011;56:267-88. doi:10.1037/a0025579.

84. van Buuren S, Boshuizen HC, Knook DL. Multiple imputation of missing blood pressure covariates in survival analysis. Stat Med. 1999;18:681-94.

85. van Buuren S, Groothuis-Oudshoorn K. MICE: multivariate imputation by chained equations in R. J Stat Softw. 2011:45:1-67.

86. Singer JD, Willett JB. Applied longitudinal data analysis: Modeling change and event occurrence. Oxford: Oxford University Press; 2003.

87. Hox JJ, Moerbeek M, van de Schoot R. Multilevel analysis: techniques and applications. Routledge; 2010.

88. Brassington GS, Atienza AA, Perczek RE, Dilorenzo TM, King AC. InterventionRelated Cognitive Versus Social Mediators of Exercise Adherence in the Elderly. Am J Prev Med. 2002;23:80-6. doi:10.1016/s0749-3797(02)00477-4.

89. Mcauley E, Jerome GJ, Marquez DX, Elavsky S, Blissmer B. Exercise Self-Efficacy in Older Adults: Social, Affective, and Behavioral Influences. Ann Behav Med. 2003:25:1-7. doi:10.1207/s15324796abm2501_01.

90. Markus H, Wurf E. The dynamic self-concept: a social psychological perspective. Annu Rev Psychol. 1987;3:299-337.

91. Wilson DK, Ellerbe C, Lawson AB, Alia KA, Meyers DC, Coulon SM, Lawman HG. Imputational modeling of spatial context and social environmental predictors of walking in an underserved community: the PATH trial. Spat spatio-temporal epidemiol. 2013:4:15-23.

92. Strath SJ, Greenwald MJ, Isaacs R, Hart TL, Lenz EK, Dondzila CJ, Swartz AM. Measured and perceived environmental characteristics are related to accelerometer defined physical activity in older adults. Int J Behav Nutr Phys Act. 2012;9:40
93. Cunningham GO, Michael YL. Concepts guiding the study of the impact of the built environment on physical activity for older adults: a review of the literature. Am J Health Promot. 2004;18:435-43.

94. Shigematsu R, Sallis J, Conway T, Saelens B, Frank L, Cain K, Chapman JE, King A. Age differences in the relation of perceived neighborhood environment to walking. Med Sci Sports Exerc. 2009;41:314-21. doi:10.1249/mss.0b013e318185496c

95. Orsega-Smith E, Payne LL, Mowen AJ, Ho CH, Godbey GC. The role of social support and self-efficacy in shaping the leisure time physical activity of older adults. J Leis Res. 2007:39:705-27.

96. Wilcox S, Castro C, King AC, Housemann R, Brownson RC. Determinants of leisure time physical activity in rural compared with urban older and ethnically diverse women in the United States. J Epidemiol Community Health. 2000;54:667-72. doi:10.1136/jech.54.9.667.

97. Van Cauwenberg J, De Donder L, Clarys P, De Bourdeaudhuij I, Buffel T, De Witte N, Dury S, Verte D, Deforche B. Relationships between the perceived neighborhood social environment and walking for transportation among older adults. Soc Sci Med. 2014;104:23-30. doi:10.1016/j.socscimed.2013.12.016.

98. Lindström M, Hanson BS, Östergren PO. Socioeconomic differences in leisure-time physical activity: the role of social participation and social capital in shaping health related behaviour. Soc Sci Med. 2001;52:441-51. doi:10.1016/s0277-9536(00)00153-2.

99. Oka RK, King AC, Young DR. Sources of social support as predictors of exercise adherence in women and men ages 50 to 65 years. Women's Health. 1994;1:161-75.

100. Resnicow K, Gobat N, Naar S. Intensifying and igniting change talk in motivational interviewing: a theoretical and practical framework. Eur Health Psychol. 2015;17:102-10.

101. Critcher CR, Dunning D. Self-affirmations provide a broader perspective on self-threat. Personal Soc Psychol Bull. 2015;41:3-18. doi:10.1177/ 0146167214554956

102. Ogden CL, Carroll MD, Kit BK, Flegal KM. Prevalence of childhood and adult obesity in the United States, 2011-2012. JAMA. 2014;311:806-14. doi:10.1001/jama.2014.732.

103. Marshall SJ, Jones DA, Ainsworth BE, Reis JP, Levy SS, Macera CA. Race/ ethnicity, social class, and leisure-time physical inactivity. Med Sci Sports Exerc. n39:44-51 doi: 10.1249/00005768-200505001-01689.

104. Ward BW, Clarke TC, Nugent CN, Schiller JS. Early release of selected estimates based on data from the 2015 National Health Interview Survey. National Center for Health Statistics. http://www.cdc.gov/nchs/data/nhis/ earlyrelease/earlyrelease201605.pdf. Accessed 15 Nov 2016.

\section{Submit your next manuscript to BioMed Central and we will help you at every step:}

- We accept pre-submission inquiries

- Our selector tool helps you to find the most relevant journal

- We provide round the clock customer support

- Convenient online submission

- Thorough peer review

- Inclusion in PubMed and all major indexing services

- Maximum visibility for your research

Submit your manuscript at www.biomedcentral.com/submit 